\title{
Association of progression-free survival with patient-reported outcomes and survival: results from a randomised phase 3 trial of
} panitumumab

\author{
S Siena ${ }^{*, 1}$, M Peeters ${ }^{2}$, E Van Cutsem ${ }^{3}$, Y Humblet ${ }^{4}$, P Conte ${ }^{5}$, E Bajetta ${ }^{6}$, D Comandini ${ }^{7}$, G Bodoky ${ }^{8}$, \\ G Van Hazel', T Salek ${ }^{10}$, M Wolf $^{\prime \prime}$, G Devercelli ${ }^{\prime \prime}$, M Woolley ${ }^{\prime \prime}$ and RG Amado ${ }^{\prime \prime}$ \\ 'Ospedale Niguarda Ca' Granda, Milan, Italy; ${ }^{2}$ Ghent University Hospital, Ghent, Belgium; ${ }^{3}$ University Hospital Gasthuisberg, Leuven, Belgium; ${ }^{4}$ St-Luc \\ University Hospital, Brussels, Belgium; ${ }^{5}$ UO Oncologia Medica - Centro Oncologico Modenese COM, Modena, Italy; ${ }^{6}$ Istituto per lo Studio a la Cura dei \\ Tumori, Milan, Italy; ${ }^{7}$ Ospedale San Martino, Genova, Italy; ${ }^{8}$ Szent László Hospital, Budapest, Hungary; ${ }^{9}$ Clinical Trials Centre, West Perth WA, Australia; \\ ${ }^{10}$ National Cancer Institute, Bratislava, Slovak Republic; " Amgen Inc., Thousand Oaks, CA, USA
}

In a randomised phase 3 trial, panitumumab significantly improved progression-free survival (PFS) in patients with refractory metastatic colorectal cancer ( $\mathrm{mCRC}$ ). This analysis characterises the association of PFS with CRC symptoms, health-related quality of life (HRQoL), and overall survival (OS). CRC symptoms (NCCN/FACT CRC symptom index, FCSI) and HRQoL (EQ-5D) were assessed for 207 panitumumab patients and 184 best supportive care (BSC) patients who had at least one post-baseline patientreported outcome (PRO) assessment. Patients alive at week 8 were included in the PRO and OS analyses and categorised by their week 8 progression status as follows: no progressive disease (no PD; best response of at least stable disease) vs progressive disease (PD). Standard imputation methods were used to assign missing values. Significantly more patients were progression free at weeks 8-24 with panitumumab vs BSC. After excluding responders, a significant difference in PFS remained favouring panitumumab $(\mathrm{HR}=0.63,95 \% \mathrm{Cl}=0.52-0.77 ; P<0.000 \mathrm{I})$. At week 8 , lack of disease progression was associated with significantly and clinically meaningful lower CRC symptomatology for both treatment groups and higher HRQoL for panitumumab patients only. Overall survival favoured no PD patients vs PD patients alive at week 8. Lack of disease progression was associated with better symptom control, HRQoL, and OS.

British Journal of Cancer (2007) 97, |469- |474. doi:| 0.1038/sj.bjc.6604053 www.bjcancer.com

Published online 27 November 2007

(C) 2007 Cancer Research UK

Keywords: panitumumab; patient-reported outcomes; quality of life; disease progression; symptom; improvement

Colorectal cancer (CRC) is the third most common cancer worldwide, with more than one million new diagnoses each year, and more than 500000 deaths annually (Parkin et al, 2005). Despite advancements in treatment for this disease which include cytotoxic agents and targeted therapies, most patients eventually progress, become symptomatic, and succumb to their disease (de Gramont et al, 2000; Douillard et al, 2000; Saltz et al, 2000; Rothenberg et al, 2003; Cunningham et al, 2004; Hurwitz et al, 2004; Saltz et al, 2004; Tournigand et al, 2004).

Progression-free survival (PFS) has been shown to correlate with overall survival (OS) in the first-line setting for metastatic colorectal cancer (mCRC) (Tournigand et al, 2004). Since disease progression is a consequence of tumour growth, and it is often associated with symptomatic progression, using PFS as a surrogate end point in CRC trials is also likely to predict clinical benefit in

\footnotetext{
* Correspondence: Professor S Siena, Ospedale Niguarda Ca' Granda, Piazza Ospedale Maggiore 3, Milan I-20I62 Italy;

E-mail: salvatore.siena@ospedaleniguarda.it

Received 6 August 2007; revised 25 September 2007; accepted 27 September 2007; published online 27 November 2007
}

the setting of refractory disease. However, the role of PFS as a predictor of OS in later lines of treatment for mCRC has not yet been demonstrated.

In mCRC, monoclonal antibodies that target the epidermal growth factor receptor (EGFR) have demonstrated efficacy (Cunningham et al, 2004; Van Cutsem et al, 2007a, b). Currently, two anti-EGFR antibodies are approved for the treatment of mCRC, panitumumab and cetuximab (Yang et al, 1999; Yarden and Sliwkowski, 2001; Foon et al, 2004). Panitumumab is a fully human monoclonal antibody that inhibits ligand binding (e.g., EGF and TGF- $\alpha$ ) and associated cellular processes that lead to tumour growth, cell survival, and metastases. A phase 3 randomised-controlled trial of panitumumab plus best supportive care (BSC) vs BSC alone in patients with mCRC who had progressed after standard therapy demonstrated that panitumumab plus BSC was well tolerated and significantly improved PFS (Van Cutsem et al, 2007a).

The clinical benefit of delaying tumour progression (i.e., PFS) was not fully explored in the primary analysis of this study. From the primary analysis of patient-reported outcomes (PROs), no significant differences in CRC symptoms and health-related quality of life (HRQoL) were seen between the two treatment groups 
(Van Cutsem et al, 2007a). Potential HRQoL and CRC symptom benefits associated with panitumumab therapy are important aspects of clinical benefit, particularly in a chemorefractory population with progressing disease. In addition, OS is a recognised standard end point in this setting. In this report, exploratory analyses were conducted that assessed the association between PFS and patient-reported CRC symptoms and HRQoL, as well as OS.

\section{PATIENTS AND METHODS}

\section{Patients and study design}

This phase 3 multicentre, open-label randomised-controlled trial evaluated the efficacy and safety of panitumumab plus BSC (panitumumab) compared with BSC alone (BSC) given every 2 weeks in patients with mCRC that had progressed on prior fluoropyrimidine, irinotecan, and oxaliplatin (Figure 1) (Van Cutsem et al, 2007a). Relevant inclusion criteria were pathologic diagnosis of metastatic colorectal adenocarcinoma, radiologic documentation of disease progression during or within 6 months following the last administration of fluoropyrimidine, irinotecan, and oxaliplatin, prior exposure to prespecified doses of irinotecan and oxaliplatin, and two or three prior chemotherapy regimens. Both criteria of disease progression and dose intensity were retrospectively centrally confirmed. Additional details of the study design and key eligibility criteria are reported in the primary publication (Van Cutsem et al, 2007a).

Objective tumour response was assessed by central radiology review using modified RECIST criteria (Therasse et al, 2000) at specified time points from weeks 8 to 48 , and every 3 months thereafter until disease progression. Responses were confirmed not less than 4 weeks after response criteria were first met. Tumour response, including stable disease, was evaluated at the first scheduled assessment (week 8). At the discretion of the investigator, patients could be evaluated for radiographic tumour assessment after developing symptoms consistent with disease progression. Best supportive care patients determined by investigator to have disease progression were allowed to receive panitumumab under a separate cross-over study (Van Cutsem et al, 2007a, b).

\section{HRQoL and CRC symptomatology assessments}

Patient-reported outcome assessments were taken at baseline, every 2 weeks or monthly during the treatment phase of the study, and at the 30-day safety follow-up visit (Table 1). CRC symptomatology was measured using the NCCN FACT Colorectal Symptom Index (FCSI) and HRQoL was measured using the EQ-5D Health Index Scale, the EQ Visual Analog Scale (VAS), and two global health items from the Global Quality of Life Scale of the European Organizations for the Research and Treatment of Cancer Quality of Life Questionnaire - Core (EORTC QLQ-C30).

The FCSI was derived as a set of brief, clinically relevant CRC symptoms for assessing symptomatic response. It comprises of the most important symptoms associated with CRC including pain, energy, diarrhoea, nausea, stomach swelling or cramps, appetite, and weight loss, and more general aspects of HRQoL such as ability to enjoy life and contentedness with QoL (Cella et al, 2003). The nine-item FCSI is scored to produce a total score. Linear transformation was used to standardise the raw score, so that the total score ranges from 0 (severely symptomatic on all symptoms assessed) to 100 (symptom-free on all symptoms assessed). For the FCSI, the minimal clinical important difference (MCID) was defined as a change in score of 4 points or more (in a scale of 0 -100) (Mathias et al, 2006). The FCSI was specifically developed to be used in CRC research and designed to be sensitive to

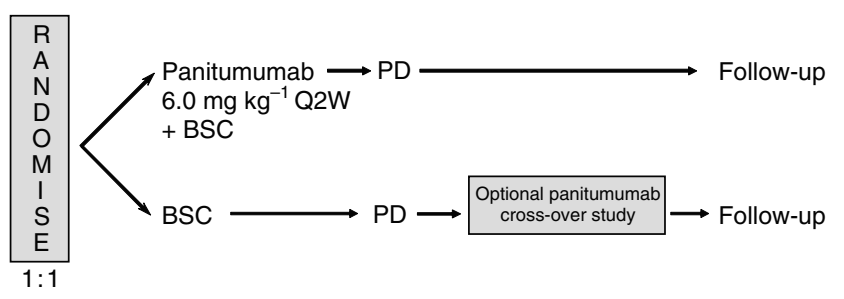

Stratification:

- ECOG score: 0-1 vs 2

- Geographic region

Figure I Phase 3 study schema.

Table I PRO assessment and schedule

\begin{tabular}{ll}
\hline PRO instrument & Assessment schedule \\
\hline FACT-FCSI & $\begin{array}{l}\text { Baseline, every 2 weeks during } \\
\text { treatment, and at the 30-day safety } \\
\text { follow-up visit } \\
\text { Baseline, monthly during treatment, and } \\
\text { at the 30-day safety follow-up visit }\end{array}$ \\
EUROQOL (EQ-5D) Health Index & \\
Scale (VAS) & \\
EORTC QLQ-C30 Global Health & \\
Status/QOL Scale & \\
\hline
\end{tabular}

symptomatic progression as experienced by patients with metastatic disease (Cella et al, 2003). The relevance of these specific symptoms also correlates well with routine clinical observations of those engaged in the care of these patients.

The EQ-5D Health Index Scale provides a preference-weighted assessment of overall QoL across five dimensions that include mobility, self-care, usual activity, pain or discomfort, and anxiety or depression. Each dimension has three possible outcomes (no problems, moderate problems, and extreme problems), with a total score ranging from 0 corresponding with death to 1 corresponding with perfect health (Walters and Brazier, 2005). Estimates for the MCID for the EQ-5D Index include a change in score of 0.074 points (Osoba et $a l, 1998$ ) and 0.08 points or more (Osoba et al, 1998; Mathias et al, 2006).

The EQ-5D Visual Analog Scale (VAS) provides an assessment of current health status on a vertical scale and ranges from 0 to 100 with 0 representing worst imaginable health state and 100 representing best imaginable health state (Brooks et al, 2003). For the EQ-5D VAS, the MCID was defined as a change in score of 5.48 points or more (Mathias et al, 2006).

The EORTC QLQ-C30 is a validated HRQoL 30-item instrument (Aaronson et al, 1993). In this study, the Global Health Status/QoL Scale of the EORTC QLQ-C30 was used. It consists of two items measuring overall health status and overall QoL. Linear transformation is used to standardise the raw score into a scale ranging from 0 to 100 with higher scores indicating better overall QoL (Fayers et al, 1995). For the Global Health Status/QoL Scale, the MCID was defined as a change in score of 7.07 points or more (Mathias et al, 2006).

\section{Statistical analysis}

The primary study end point was PFS by blinded central radiology assessment. The primary analysis of PFS included tumour assessments after crossover to panitumumab for BSC patients if disease progression was not centrally confirmed while the patient 
received BSC alone. Secondary end points included best objective response by blinded central review (prespecified for testing), OS, and PROs as described above. To assess whether the treatment differences in PFS were due to patients with an objective response, a post-hoc sensitivity analysis of PFS that removed responding patients in the panitumumab group (i.e., patients with a best response of at least partial response) was conducted to evaluate the contribution of non-responding patients on the treatment effect with panitumumab. Statistical analyses for the primary and secondary end points have been described previously (Van Cutsem et al, 2007a, b).

The objective of the analyses presented herein was to evaluate the association between delaying tumour progression (i.e., PFS) and CRC symptoms, HRQoL, and OS. For PRO analyses (i.e., CRC symptoms and HRQoL), patients were included if they had at least one post-baseline PRO assessment (the PRO all enrolled analysis set). Additionally, to help reduce bias, patients who died prior to week 8 were excluded from the PRO analysis. Patients were categorised into one of two groups based on progression status as of week 8 as follows: (1) patients who were progression free (i.e., had a best confirmed response of at least stable disease); or (2) patients with tumour progression (i.e., had less than stable disease).

$t$-Tests and least-squares estimates were calculated for differences in PRO measures at weeks 4, 8, 12, and 16 controlling for baseline score by progression status as of week 8 (no tumour progression $v s$ tumour progression) within each treatment arm. For each treatment group, descriptive statistics of point estimates of scores over time for all instruments and of the difference in scores between the two tumour progression groups over time for all instruments were summarised.

Missing PRO data were imputed using the following two methods: last value carried forward (LVCF) method and a slope method (Fairclough, 2002; Fielding et al, 2006). For the LVCF method, missing observations were replaced with the last observed value carried forward for reasons other than death or zero value carried forward at death. Additional rules for the LVCF method were as follows: (1) patients missing values in between two observed values had the earlier observed value carried forward unless the subsequent observed value occurred after disease progression, in which case the later observed value was carried backward; and (2) if the baseline data were missing then the missing data were imputed using the first observation carried backwards.

The slope method applied forward linear interpolation of observed data to impute missing data. Time was measured relative to randomisation with observed data assigned to the day it was obtained, and the day of a missed assessment is assigned to the day the assessment was scheduled per protocol. The predicted value from a linear regression of observed data prior to a missed assessment was used to impute a value at the time of the missed assessment. Prior imputed values were not used to impute subsequent values. If there was only one observed value prior to a missed assessment, then the last value was carried forward to the missed assessment. If the first scheduled assessment was missing, then it was not imputed.

For OS, within each treatment group, survival was examined among patients surviving to at least week 8 according to their progression status as of week 8 . A Cox regression model was used to examine the correlation between time to radiologic progression (TTP) and time to death (TTD) among all patients. Time to radiologic progression was defined as the time from randomisation to radiologic disease progression per modified-RECIST by blinded central review. Patients who died without radiologic progression were censored at their last radiologic assessment of TTP. The model included indicators for the randomisation factors (ECOG performance score and geographic region) and a time-dependent covariate for radiologic progressive disease (PD).

\section{RESULTS}

\section{Demographics}

In this phase 3 trial, 463 patients were randomised, 231 patients to panitumumab and 232 patients to BSC (Van Cutsem et al, 2007a). Median follow-up time for survival (enrollment to data cutoff for analysis) for all patients was 72 weeks (range $=52-113$ ). In the BSC group, $176(76 \%)$ patients received panitumumab under the crossover study (Van Cutsem et al, 2007b).

In the all randomised analysis set, $22(10 \%)$ of panitumumab patients had a partial response and $62(27 \%)$ patients had stable disease. Of the BSC patients, no patients had an objective response and $23(10 \%)$ patients had stable disease. Disease control (the sum of objective response and stable disease rates) was seen in $84(36 \%)$ panitumumab patients and $23(10 \%)$ BSC patients.

For the PRO analyses, 207 (90\%) panitumumab patients and 184 (79\%) BSC patients had at least one post-baseline PRO assessment and comprised the PRO All Enrolled analysis set (Table 2). As expected from the higher rate of discontinuation because of disease progression in the BSC group, a higher percentage of panitumumab patients had evaluable PRO data compared with the BSC group from week 4 onwards. At week 4, EQ-5D data were available for $91 \%$ of panitumumab patients and $70 \%$ of BSC patients; by week 16, data were available for $30 \%$ and $4 \%$ of patients, respectively. The proportion of patients with available data for the FCSI at weeks 4 and 16 for each treatment group were similar as that for the EQ-5D at those respective time points.

\section{Contribution of stable disease on PFS}

To evaluate the importance of achieving stable disease in this population, an analysis was conducted where panitumumab patients who had an objective response were excluded from the primary analysis of PFS (all randomised patients, panitumumab vs BSC). A significant difference in PFS remained for panitumumab over BSC (hazard ratio $=0.63,95 \% \mathrm{CI}=0.52-0.77 ; P<0.0001$ ) (Figure 2). These data indicated that improvement in PFS was not derived solely from the subset of patients with a best response of partial response. Indeed, $80 \%$ of the overall treatment effect could be accounted for by panitumumab patients without an objective response, specifically by patients with stable disease.

Table 2 Patient analysis sets and PRO data availability

\begin{tabular}{|c|c|c|}
\hline & $\begin{array}{l}\text { Panitumumab } \\
\text { plus BSC }\end{array}$ & BSC alone \\
\hline Total randomised $(n)$ & 231 & 232 \\
\hline PRO all enrolled analysis set ( $n$ ) & 207 & 184 \\
\hline $\begin{array}{l}\text { PRO all enrolled analysis set and alive at week } 8 \text {, } \\
\text { EQ-5D (n) }\end{array}$ & 179 & 164 \\
\hline \multicolumn{3}{|l|}{ Patients completing EQ-5D (n) } \\
\hline Week 4 & 189 & 129 \\
\hline Week 8 & | | | & 47 \\
\hline Week 12 & 91 & 14 \\
\hline Week 16 & 62 & 7 \\
\hline $\begin{array}{l}\text { PRO all enrolled analysis set and alive at week } 8 \text {, } \\
\text { FCSI (n) }\end{array}$ & 181 & 166 \\
\hline \multicolumn{3}{|l|}{ Patients completing FCSI subscale (n) } \\
\hline Week 4 & 190 & 130 \\
\hline Week 8 & 112 & 48 \\
\hline Week 12 & 90 & 14 \\
\hline Week 16 & 62 & 7 \\
\hline
\end{tabular}




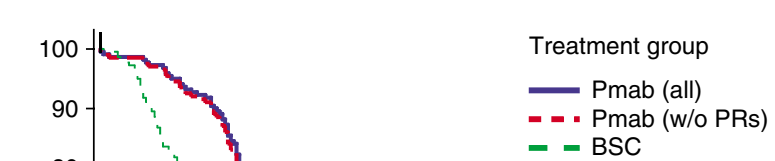

Hazard ratio (Pmab all:BSC) ${ }^{\star}=0.54$

$(95 \% \mathrm{Cl}=0.44-0.66)$

Hazard ratio (Pmab w/o PR:BSC) ${ }^{\star \star}=0.63$

$(95 \% \mathrm{Cl}=0.52-0.77)$

$\begin{array}{llllllllllllllllllllllllllll}\text { Patients at risk: } & 231 & 217 & 209 & 197 & 118 & 85 & 76 & 65 & 49 & 41 & 40 & 40 & 31 & 22 & 19 & 19 & 13 & 8 & 8 & 8 & 5 & 2 & 2 & 1 & 1 & 1\end{array}$

$\begin{array}{lllllllllllllllllllllllllllll}\text { Pmab (w/o PRs) } & 212 & 198 & 190 & 178 & 99 & 66 & 57 & 46 & 33 & 26 & 25 & 25 & 21 & 14 & 12 & 12 & 8 & 5 & 5 & 5 & 3 & 1 & 1 & 0 & 0 & 0\end{array}$

$\begin{array}{llllllllllllllllllllllllllllll}\text { BSC alone } & 232 & 209 & 175 & 149 & 75 & 41 & 31 & 20 & 17 & 11 & 7 & 7 & 7 & 4 & 4 & 3 & 3 & 3 & 2 & 1 & 1 & 1 & 1 & 1 & 1 & 0\end{array}$

*Panitumumab (all) and BSC curves are from the primary analysis for PFS (Van Cutsem et al, 2007).

${ }^{\star \star}$ For panitumumab (w/o PR): BSC group; adjusted for ECOG and region. Pmab=panitumumab

Figure 2 Sensitivity analysis of progression-free survival (PFS) with and without responders in the panitumumab group.

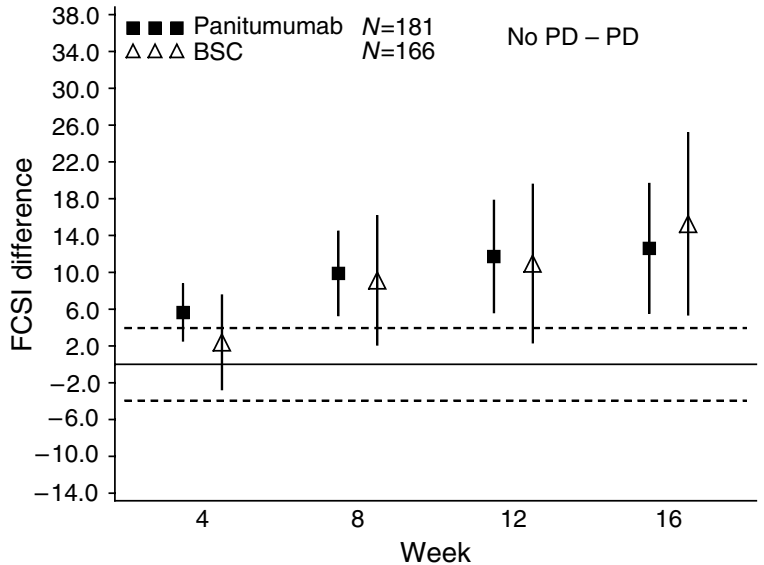

Note: dashed line at -3.94 represents a minimum clinical important difference (MCID) anchored to $a \frac{1}{2}$ point change in ECOG score (Mathias et al, 2006). Difference is for no PD - PD.

The landmark analysis included patients surviving at least 56 days.

Figure 3 Mean FACT-FCSI difference $(95 \% \mathrm{Cl})$ in scores by progression status at week 8 (central review, patient-reported outcome (PRO) all enrolled, landmark analysis).

\section{Association between PFS and disease-related symptoms and HRQoL}

Patient-reported outcomes were evaluated in each treatment group for patients alive at week 8 and stratified by tumour progression status as of week 8. For both the FCSI and EQ-5D Health Index, among panitumumab patients, those who were progression free at week 8 maintained mean scores throughout treatment while those with tumour progression at week 8 had a steady decline in the mean scores throughout treatment (data not shown).

The difference in the FCSI scores between patients who were progression free (no PD) and those with progression (PD) at week

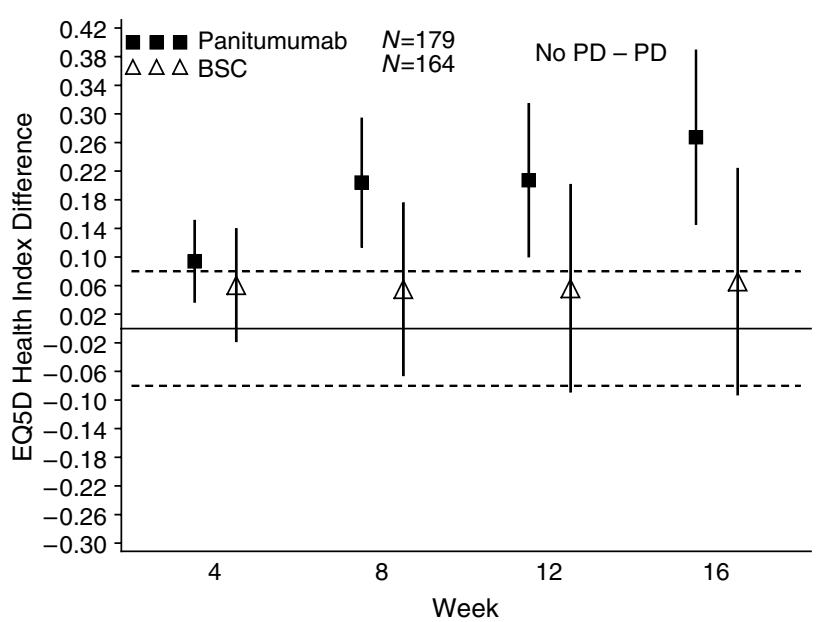

Note: dashed line at -0.08 represents a minimum clinical important difference (MCID) anchored to $a^{1 / 2}$ point change in ECOG score. (Mathias et al, 2006). Difference is for no PD - PD.

The landmark analysis included patients surviving at least 56 days.

Figure 4 Mean EQ-5D Health Index Difference $(95 \% \mathrm{Cl})$ in scores by progression status at week 8 (central review, patient-reported outcome (PRO) all enrolled, landmark analysis).

8 was evaluated in both treatment groups (Figure 3). For both panitumumab or BSC groups, achieving at least stable disease at week 8 (i.e., being progression free) was associated with significant and clinically meaningful improvement in control of diseaserelated symptoms at all time points (weeks 4, 8, 12, and 16) (Figure 3). The lower limits of the $95 \%$ confidence intervals excluded 0 (i.e., statistical significance) and the point estimates exceeded the MCID of -4 points (i.e., clinically meaningful) at all time points for the panitumumab group and at weeks 8 to 16 for the BSC group.

For the EQ-5D Health Index, the difference in scores for panitumumab patients alive at week 8 who did not have tumour 


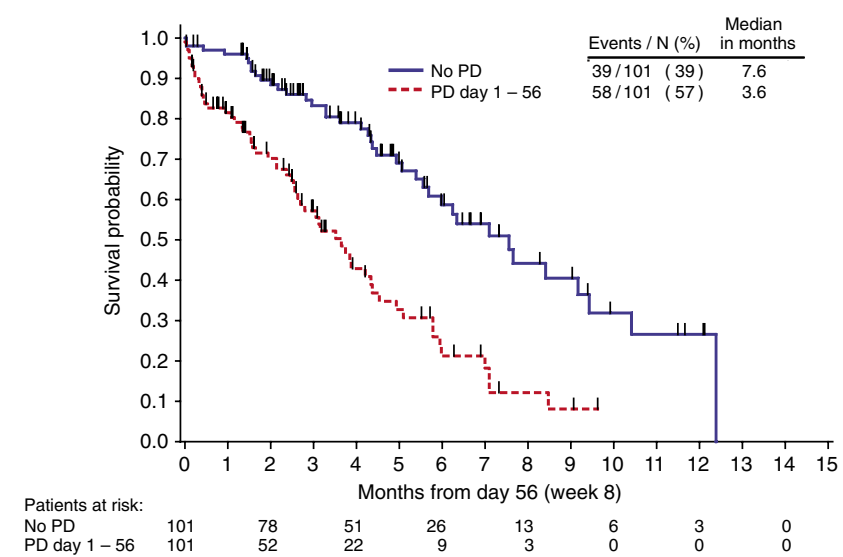

Figure 5 Overall survival (OS) in subset of panitumumab patients alive at week 8 and categorised by tumour progression status at week 8 .

progression minus those with progression was significantly and clinically meaningful at all time points (Figure 4). For BSC patients, the difference in scores between the tumour progression groups was not significant or clinically meaningful (Figure 4). Lack of disease progression with panitumumab for patients alive at week 8 was associated with better HRQoL.

Results for the FCSI and EQ-5D for all treatment groups were similar regardless of imputation method. Additionally, similar results for panitumumab and BSC patients stratified by tumour progression status were observed for the EQ-5D VAS and EORTC Global Scale (data not shown).

\section{Association of tumour progression status on OS in the panitumumab patients}

Panitumumab patients who were alive at week 8 without PD had a median TTD of 7.6 months (Figure 5). For panitumumab patients alive with a PD at week 8, the median TTD was 3.6 months. For BSC patients who were alive at week 8 , those without PD had a median TTD of 8.6 months $v s$ those with PD who had a median TTD of 4.3 months (data not shown).

\section{DISCUSSION}

This exploratory analysis was conducted to evaluate the association of tumour progression status with HRQoL. Here, we first evaluated the contribution of stable disease on the overall effect of panitumumab on PFS. These analyses revealed that $80 \%$ of the treatment effect of panitumumab on PFS was retained after removing patients that responded to the drug. These results indicate that the treatment benefit with panitumumab is obtained in patients with disease stabilisation. These results are of interest given that patients in this trial had disease progression after exposure to adequate chemotherapy dose intensity that was adjudicated independently.

It is hypothesised that panitumumab induced clinical benefit by halting disease progression. A similar effect has been observed for other targeted compounds used in monotherapy (Ratain et al, 2006; Escudier et al, 2007). Therefore, we then evaluated the association of PFS and clinical outcomes in patients with mCRC refractory to standard chemotherapy regimens. There was a significant and clinically meaningful association between being progression free and better HRQoL, CRC symptomatology, and OS in panitumumab patients. An association between improved PFS and favourable OS prognosis was also observed in the BSC arm, potentially reflecting a subpopulation with more indolent disease. However, compared to BSC alone, treatment with panitumumab resulted in approximately $20 \%$ more patients who were progression free at weeks 8,12 , and 16 (Van Cutsem et al, $2007 \mathrm{a}, \mathrm{b})$. Although more patients were rendered progression free with panitumumab compared to BSC, and being progression free was associated with a favourable OS prognosis, these progressionfree rate differences did not translate into differences in OS when all patients were compared (Van Cutsem et al, 2007a,b), possibly due to the effect of early crossover of patients in the BSC to panitumumab treatment. Indeed, $76 \%$ of patients in the BSC arm crossed over to receive panitumumab at a median time of 7.0 weeks. In these patients, panitumumab treatment was associated with similar clinical activity as that in the phase 3 study (Van Cutsem et al, 2007a, b).

The reasons underlying the association between progression status and HRQoL in the panitumumab arm may relate to the overall effects of panitumumab on tumour growth arrest. Although objective responses were observed in $10 \%$ of patients, a larger number of patients within the stable disease population also had reductions in tumour burden. Indeed, in panitumumab patients with stable disease, there was a median decrease in maximum target lesion size of approximately $12 \%$ compared to baseline, whereas BSC patients with stable disease had a median increase of approximately 7\% (Amgen, data on file). Overall, the majority of patients achieving a best response of at least stable disease in the panitumumab group had a reduction in tumour volume, which was associated with symptom improvement.

Missing data for QoL end points was largely due to disease progression (and therefore QoL data collection halted) in this advanced-stage population, especially among the BSC patients, $70 \%$ of whom had disease progression by week 8 (and subsequently crossed over to panitumumab therapy in the extension trial). By using either of the two imputation methods, LVCF and slope, the true effect on the PROs by treatment may have been underestimated. With the LVCF method, imputation of data halts progression at dropout or crossover and carries forward the predropout assessment throughout the study, with zero carried forward at death. This method may bias the results in favour of a treatment that results in more dropouts associated with morbidity. In this case it can result in bias by imputing potentially higher scores in the BSC patient than the panitumumab patients. In some settings, the slope method may be more conservative and less biased towards either treatment group, and imputation of a score of zero at death with the LVCF method may be biased against groups with high death rates. These limitations do not seem to have affected the overall findings as results were consistent across imputation methods. However, these imputation methods ignore the effect of panitumumab received after crossover on QoL measures, as these end points were not measured in the crossover extension trial.

These results further suggest that halting disease progression is associated with clinical benefit of sustained or improved QoL and prolonged survival in patients with chemorefractory mCRC. This hypothesis should be tested prospectively in randomised-controlled trials. Further studies are ongoing to evaluate the benefits of panitumumab in subsets of patients with different molecular characteristics of resistance or sensitivity to this targeted therapeutic agent (Moroni et al, 2005; Lievre et al, 2006; Benvenuti et al, 2007; Sartore-Bianchi et al, 2007) as well as in earlier lines of therapy.

\section{ACKNOWLEDGEMENTS}

We acknowledge the patients and their family and friends for participation in this study and to all study investigators and their study staffs. We also acknowledge the following individuals from Amgen Inc.: Steve Dahlberg, MS, for critical review of the manuscript and Mee Rhan Kim, $\mathrm{PhD}$, for assistance with the preparation of this manuscript. This study was supported by Amgen Inc. Salvatore Siena is partly supported by OCGO Fondazione, Milan, Italy. 


\section{REFERENCES}

Aaronson NK, Ahmedzai S, Bergman B, Bullinger M, Cull A, Duez NJ, Filiberti A, Flechtner H, Fleishman SB, de Haes JC, Kaasa S, Klee M, Osoba D, Razavi D, Rofe PB, Schraub S, Sneeuw K, Sullivan M, Takeda F (1993) The European Organization for Research and Treatment of Cancer QLQ-C30: a quality-of-life instrument for use in international clinical trials in oncology. J Natl Cancer Inst 85: 365-376

Benvenuti S, Sartore-Bianchi A, Di Nicolantonio F, Zanon C, Moroni M, Veronese S, Siena S, Bardelli A (2007) Oncogenic activation of the RAS/ RAF signaling pathway impairs the response of metastatic colorectal cancers to anti-epidermal growth factor receptor antibody therapies. Cancer Res 67: 2643-2648

Brooks R, Rabin R, de Charro F (2003) The Measurement and Valuation of Health Status Using EQ-5D: a European Perspective. New York, NY: Kluwer Academic

Cella D, Paul D, Yount S, Winn R, Chang CH, Banik D, Weeks J (2003) What are the most important symptom targets when treating advanced cancer? A survey of providers in the National Comprehensive Cancer Network (NCCN). Cancer Invest 21: 526-535

Cunningham D, Humblet Y, Siena S, Khayat D, Bleiberg H, Santoro A, Bets D, Mueser M, Harstrick A, Verslype C, Chau I, Van Cutsem E (2004) Cetuximab monotherapy and cetuximab plus irinotecan in irinotecan-refractory metastatic colorectal cancer. $N$ Engl J Med 351: $337-345$

de Gramont A, Figer A, Seymour M, Homerin M, Hmissi A, Cassidy J, Boni C, Cortes-Funes H, Cervantes A, Freyer G, Papamichael D, Le Bail N, Louvet C, Hendler D, de Braud F, Wilson C, Morvan F, Bonetti A (2000) Leucovorin and fluorouracil with or without oxaliplatin as first-line treatment in advanced colorectal cancer. J Clin Oncol 18: 2938-2947

Douillard JY, Cunningham D, Roth AD, Navarro M, James RD, Karasek P, Jandik P, Iveson T, Carmichael J, Alakl M, Gruia G, Awad L, Rougier P (2000) Irinotecan combined with fluorouracil compared with fluorouracil alone as first-line treatment for metastatic colorectal cancer: a multicentre randomised trial. Lancet 355: $1041-1047$

Escudier B, Eisen T, Stadler WM, Szczylik C, Oudard S, Siebels M, Negrier S, Chevreau C, Solska E, Desai AA, Rolland F, Demkow T, Hutson TE, Gore M, Freeman S, Schwartz B, Shan M, Simantov R, Bukowski RM (2007) Sorafenib in advanced clear-cell renal-cell carcinoma. $N$ Engl J Med 356: $125-134$

Fairclough DL (2002) Design and analysis of quality of life studies in clinical trials. Interdisciplinary statistics. Chapman \& Hall/CRC

Fayers P, Aaranson NK, Njordal K, Sullivan M \& Group obotEQoLS (1995) EORTC QLQ-C30 Scoring Manual. Brussels, Belgium: EORTC Data Centre

Fielding S, Fayers PM, Loge JH, Jordhøy MS, Kaasa S (2006) Methods for handling missing data in palliative care research. Palliat Med 20: $791-798$

Foon KA, Yang XD, Weiner LM, Belldegrun AS, Figlin RA, Crawford J, Rowinsky EK, Dutcher JP, Vogelzang NJ, Gollub J, Thompson JA, Schwartz G, Bukowski RM, Roskos LK, Schwab GM (2004) Preclinical and clinical evaluations of ABX-EGF, a fully human anti-epidermal growth factor receptor antibody. Int $J$ Radiat Oncol Biol Phys 58: 984-990

Hurwitz H, Fehrenbacher L, Novotny W, Cartwright T, Hainsworth J, Heim W, Berlin J, Baron A, Griffing S, Holmgren E, Ferrara N, Fyfe G, Rogers B, Ross R, Kabbinavar F (2004) Bevacizumab plus irinotecan, fluorouracil, and leucovorin for metastatic colorectal cancer. $N$ Engl J Med 350: 2335-2342

Lievre A, Bachet JB, Le Corre D, Boige V, Landi B, Emile JF, Cote JF, Tomasic G, Penna C, Ducreux M, Rougier P, Penault-Llorca F, LaurentPuig P (2006) KRAS mutation status is predictive of response to cetuximab therapy in colorectal cancer. Cancer Res 66: $3992-3995$

Louvet C, de Gramont A, Tournigand C, Artru P, Maindrault-Goebel F, Krulik M (2001) Correlation between progression free survival and response rate in patients with metastatic colorectal carcinoma. Cancer 91: $2033-2038$

Mathias S, Pritchard ML, Colwell HH, Lu J, Wright N (2006) What is the minimal clinically important difference and responsiveness of a patient- reported outcome questionnaire for metastatic colorectal cancer? Annals Oncol 17(Suppl 9), Abstract no. 349P

Moroni M, Veronese S, Benvenuti S, Marrapese G, Sartore-Bianchi A, Di Nicolantonio F, Gambacorta M, Siena S, Bardelli A (2005) Gene copy number for epidermal growth factor receptor (EGFR) and clinica response to antiEGFR treatment in colorectal cancer: a cohort study. Lancet Oncol 6: 279-286

Osoba D, Rodrigues G, Myles J, Zee B, Pater J (1998) Interpreting the significance of changes in health-related quality-of-life scores. J Clin Oncol 16: $139-144$

Parkin DM, Bray F, Ferlay J, Pisani P (2005) Global cancer statistics, 2002. CA Cancer J Clin 55: 74-108

Ratain MJ, Eisen T, Stadler WM, Flaherty KT, Kaye SB, Rosner GL, Gore M, Desai AA, Patnaik A, Xiong HQ, Rowinsky E, Abbruzzese JL, Xia C, Simantov R, Schwartz B, O’Dwyer PJ (2006) Phase II placebo-controlled randomized discontinuation trial of sorafenib in patients with metastatic renal cell carcinoma. J Clin Oncol 24: 2505-2512

Rothenberg ML, Oza AM, Bigelow RH, Berlin JD, Marshall JL, Ramanathan RK, Hart LL, Gupta S, Garay CA, Burger BG, Le Bail N, Haller DG (2003) Superiority of oxaliplatin and fluorouracil-leucovorin compared with either therapy alone in patients with progressive colorectal cancer after irinotecan and fluorouracil-leucovorin: interim results of a phase III trial. J Clin Oncol 21: 2059-2069

Saltz LB, Cox JV, Blanke C, Rosen LS, Fehrenbacher L, Moore MJ, Maroun JA, Ackland SP, Locker PK, Pirotta N, Elfring GL, Miller LL (2000) Irinotecan plus fluorouracil and leucovorin for metastatic colorectal cancer. Irinotecan Study Group. $N$ Engl J Med 343: 905 -914

Saltz LB, Meropol NJ, Loehrer Sr PJ, Needle MN, Kopit J, Mayer RJ (2004) Phase II trial of cetuximab in patients with refractory colorectal cancer that expresses the epidermal growth factor receptor. J Clin Oncol 22: $1201-1208$

Sartore-Bianchi A, Moroni M, Veronese S, Carnaghi C, Bajetta E, Luppi G, Sobrero A, Baron C, Cascinu S, Colucci G, Cortesi E, Nichelatti M, Gambacorta M, Siena S (2007) Epidermal growth factor receptor gene copy number and clinical outcome of metastatic colorectal cancer treated with panitumumab. J Clin Oncol 25: 3238-3245

Therasse P, Arbuck SG, Eisenhauer EA, Wanders J, Kaplan RS, Rubinstein L, Verweij J, Van Glabbeke M, van Oosterom AT, Christian MC, Gwyther SG (2000) New guidelines to evaluate the response to treatment in solid tumors. European Organization for Research and Treatment of Cancer, National Cancer Institute of the United States, National Cancer Institute of Canada. J Natl Cancer Inst 92: 205-216

Tournigand C, Andre T, Achille E, Lledo G, Flesh M, Mery-Mignard D, Quinaux E, Couteau C, Buyse M, Ganem G, Landi B, Colin P, Louvet C, de Gramont A (2004) FOLFIRI followed by FOLFOX6 or the reverse sequence in advanced colorectal cancer: a randomized GERCOR study. J Clin Oncol 22: 229-237

Van Cutsem E, Peeters M, Siena S, Hendlisz A, Neyns B, Canon J-L, Van Laethem J-L, Maurel J, Richardson G, Wolf M, Amado RG (2007a) An open-label, randomized, phase 3 clinical trial of panitumumab plus best supportive care versus best supportive care in patients with chemotherapy-refractory metastatic colorectal cancer. J Clin Oncol 25: $1658-1664$

Van Cutsem E, Siena S, Humblet Y, Canon J-L, Maurel J, Bajetta E, Neyns B, Kotasek D, Santoro A, Scheithauer W, Spadafora S, Amado RG, Hogan N, Peeters M (2007b) An open-label, single-arm study assessing safety and efficacy of panitumumab in patients with metastatic colorectal cancer refractory to standard chemotherapy. Annals Oncol, [Epub ahead of print]

Walters SJ, Brazier JE (2005) Comparison of the minimally important difference for two health state utility measures: EQ-5D and SF-6D. Qual Life Res 14: $1523-1532$

Yang XD, Jia XC, Corvalan JR, Wang P, Davis CG, Jakobovits A (1999) Eradication of established tumors by a fully human monoclonal antibody to the epidermal growth factor receptor without concomitant chemotherapy. Cancer Res 59: 1236-1243

Yarden Y, Sliwkowski MX (2001) Untangling the ErbB signalling network. Nat Rev Mol Cell Biol 2: 127-137 